\title{
Twin-to-twin Transfusion Syndrome: An Overview
}

\author{
Richa Saxena ${ }^{1}$, Kanav Midha ${ }^{2}$
}

\begin{abstract}
Twin-to-twin transfusion syndrome (TTTS) is a severe problem that affects $10-15 \%$ of monochorionic (MC) multiple pregnancies. Connecting placental vessels on chorionic plate between donor and recipient twin is accountable for inequality of blood flow. There is an indication for the superiority of fetoscopic laser ablation over serial amnioreductions regarding survival and neurological outcome for stages II-IVTTTS. However, the optimal management of stage I is still debated. In this review, we discuss the basics of twin gestation, optimal management, pathophysiology, long-term neurodevelopmental outcome, and future aspects of TTTS.

Keywords: Dizygotic, Fetus, Gestation, Monozygotic, Twin-twin transfusion syndrome.

World Journal of Anemia (2018): 10.5005/jp-journals-10065-0041
\end{abstract}

\section{INTRODUCTION}

Development of two or more embryos simultaneously in a pregnant uterus is termed as "multifetal gestation." Development of two fetuses (whether through monozygotic or dizygotic fertilization) simultaneously is known as twin gestation; development of three fetuses simultaneously as triplets; four fetuses as quadruplets; five fetuses as quintuplets, and so on. The incidence of twin gestation is about 1 per 80 live births. The incidence varies among different countries and ethnic groups, with the incidence being highest in African countries, lowest in Japan and intermediate among Caucasians. According to Hellen's rule, frequency of twins is 1 in 80; the frequency of triplets is 1 in 802; the frequency of quadruplets is 1 in 803 , and so on. The exact cause of multifetal gestation is not known. ${ }^{1-3}$

In the past 30 years, rates of twin pregnancy have increased much in high-income or middle-income countries owing to a more advanced maternal age to become pregnant, a decrease in fertility and improved use of assisted reproductive techniques. ${ }^{4-6}$

It is a well-established fact that twin pregnancy is linked with higher maternal and perinatal risks. The maternal adaptation to a twin pregnancy indicates several complications. Maternal death associated with a twin pregnancy is 2.5 -fold higher than in a singleton pregnancy. The rate of perinatal mortality is two to three times higher in twins than among singleton newborn infants, mostly due to low birthweight, preterm birth, fetal growth restriction, and intrapartum anoxia.,8

\section{Types of Twin Gestation ${ }^{9-15}$ \\ Dizygotic Twins}

When two or more ova are fertilized by sperms, the result is development of dizygotic twins or nonidentical twins or fraternal twins. As a result of being fertilized by two separate sperms, the two embryos can be of different sexes. Furthermore, in dizygotic twins the two embryos have separate placentae and there is no communication between the fetal vessels of the two embryos (Fig. 1).

\section{Monozygotic Twins}

Monozygotic twins are formed due to the division of a single fertilized egg (Fig. 2). In monozygotic multiple pregnancies,
1Jaypee Brothers Medical Publishers, New Delhi, India

${ }^{2}$ Department of Pharmaceutical Sciences, Chitkara University, Chandigarh, India

Corresponding Author: Richa Saxena, Jaypee Brothers Medical Publishers, New Delhi, India, Phone:+91 9971234834, e-mail:synapse94@ hotmail.com

How to cite this article: Saxena R, Midha K. Twin-to-twin Transfusion Syndrome: An Overview. World J Anemia 2018;2(3-4):96-102.

Source of support: Nil

Conflict of interest: None

different types can result depending on the timing of the division of the ovum (Fig. 3).

\section{Diamniotic Dichorionic Monozygotic Twin Pregnancy}

The embryo splits at or before 3 days of gestation. This results in development of two chorions and two amnions. There is a development of two distinct placentae or a single fused placenta. This type of monozygotic twin accounts for nearly $8 \%$ of all twin gestations (Fig. 4A).

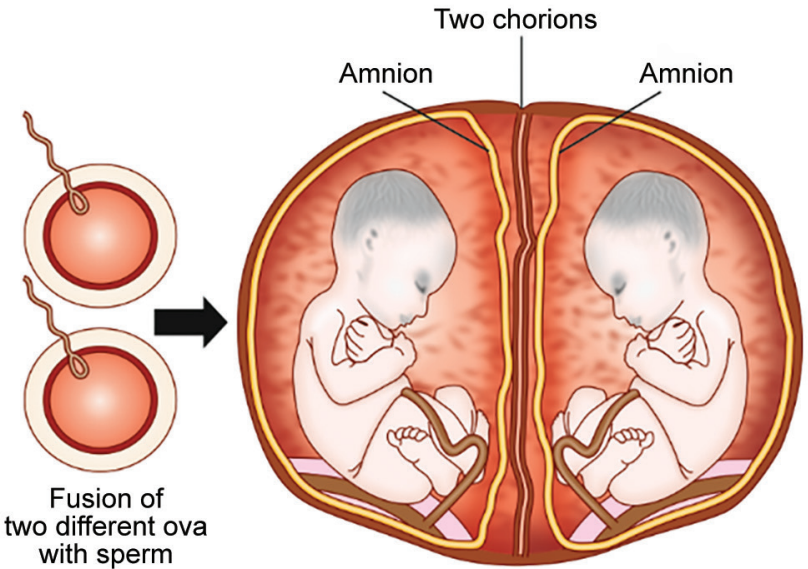

Fig. 1: Formation of dizygotic twins

() The Author(s). 2018 Open Access This article is distributed under the terms of the Creative Commons Attribution 4.0 International License (https://creativecommons. org/licenses/by-nc/4.0/), which permits unrestricted use, distribution, and non-commercial reproduction in any medium, provided you give appropriate credit to the original author(s) and the source, provide a link to the Creative Commons license, and indicate if changes were made. The Creative Commons Public Domain Dedication waiver (http://creativecommons.org/publicdomain/zero/1.0/) applies to the data made available in this article, unless otherwise stated. 


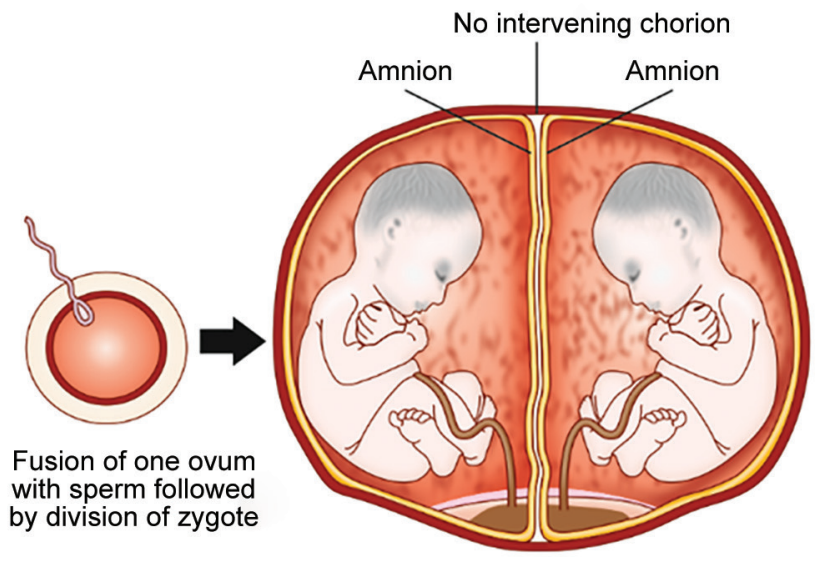

Fig. 2: Formation of monozygotic twins (MCDA)

\section{Diamniotic Monochorionic Monozygotic Twin Pregnancy}

The cleavage division is delayed until the formation of inner cell mass and the embryo splits between 4 days and 7 days of gestation. This results in development of a single chorion and two amnions. Nearly $20 \%$ of all twins are of this type (Fig. 4B).

\section{Monoamniotic Monochorionic Monozygotic Twin Pregnancy}

The embryo splits between 8 days and 12 days of gestation. This results in development of one chorion and one amnion. Such types of monozygotic twins are rare, accounting for less than $1 \%$ of all twin gestations (Fig. 4C).

\section{Conjoined or Siamese Monozygotic Twin Pregnancy}

The embryo splits at or after 13 days of gestation, resulting in development of conjoined twins, which share a particular body part with each other. Development of such type of monozygotic twins is extremely rare. Joining of the twins can begin at either pole and may be dorsal, ventral, and lateral. Of the various types of conjoined twins, parapagus twins (laterally joined) are the most common type.

\section{Twin-to-twin Transfusion}

This is a rare complication that can occur in Monochorionic (MC) twins, which causes the blood to pass from one twin to the other (Fig. 5). This usually occurs due to the presence of placental vascular communication. The placental vascular anastomoses responsible for the development of TTTS could be from artery-to-artery (A-A); artery-to-vein (A-V); or from vein-to-vein (V-V) (Fig. 6). As a result of the vascular communication, one of the twins, which donates blood (donor twin) becomes thin and undernourished, while the other twin who receives blood (recipient twin) grows at the expense of donor twin. The donor twin in TTTS usually shows poor growth, oliguria, anemia and hyperproteinemia, and low or absent liquor, resulting in development of oligohydramnios, etc. (Flowchart 1). With the severe disease, the donor may not produce any urine, resulting in oligohydramnios and nonvisualization of urinary bladder on ultrasound examination. In these cases, the twin may become wrapped by its amniotic membrane, resulting in the formation of a "stuck" twin. On the other hand, the recipient twin shows polyuria, polyhydramnios, and an enlarged urinary bladder. In the long run, this twin frequently develops polycythemia, biventricular cardiac hypertrophy, and diastolic dysfunction with tricuspid regurgitation. The death of this twin eventually occurs due to congestive heart failure.

\section{Classification of identical twins by time of splitting}

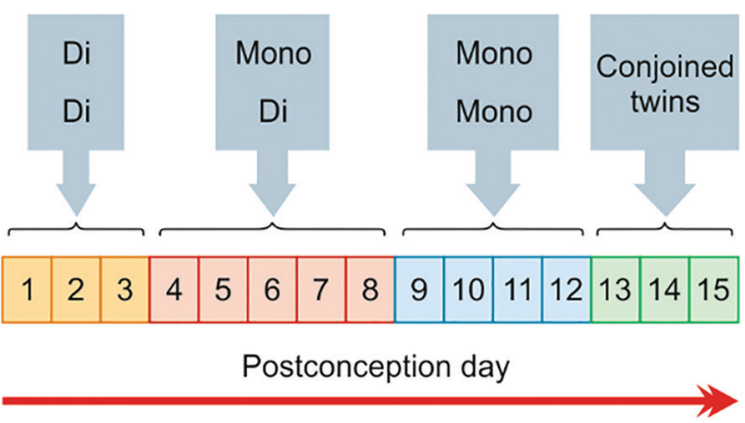

Fig. 3: Formation of different types of monozygotic twins ( $\mathrm{Di} \mathrm{Di}$, diamniotic dichorionic; Mono Di, monochorionic diamniotic; Mono Mono: monoamniotic monochorionic)

Twin-twin transfusion syndrome (TTTS) is comprised of high risk of mortality and morbidity and complicates $15 \%$ of monochorionicdiamniotic (MCDA) twin pregnancies. ${ }^{16}$ Twin-to-twin transfusion syndrome (TTTS) is triggered by unstable blood flow from the donor to the recipient via placental anastomoses. ${ }^{17,18}$ Twin-to-twin transfusion syndrome diagnosis typically presents as oligohydramniospolyhydramnios sequence and is based on ultrasound..$^{19}$ When left untreated, TTTS is $80-100 \%$ harmful for fetuses; nevertheless, the increased use of interventions such as laser coagulation of the intertwin anastomoses (laser therapy) has caused significantly enhanced survival rates for both twins (69.5\%) or at least 1 twin (89.5\%). ${ }^{20}$

Zhao et al. examined $235 \mathrm{MC}$ placentas in untreated cases. Color dye injection after birth was made to examine the incidence, type, location, and size of the placental anastomoses. The number of superficial arterio-arterial anastomoses with bidirectional blood flow between the two cord insertions was substantially lower (47\%) in TTTS cases in analogy to uncomplicated cases (96\%). To add-on, if artery-to-artery connections were present in TTTS placentas, the median diameter was suggestively thinner, and they were located more centrally in contrast to cases without TTTS. These conclusions emphasize the exceptional role of the MC placenta and its vascular connections between the twins' umbilicoplacental circulations in the pathophysiology of TTTS. ${ }^{21}$

\section{Ultrasound Findings}

The fundamental diagnostic criterion in TTTS is the finding of oligohydramnios in one twin and polyhydramnios in the other twin belonging to $\mathrm{MC}$ twin gestation. The criterion for the diagnosis of oligohydramnios is no fluid or a pocket of fluid less than $2 \mathrm{~cm}$ in its largest diameter. The criterion for the diagnosis of polyhydramnios is a pocket of fluid $8 \mathrm{~cm}$ or more in its largest diameter. Almost $80-90 \%$ of cases of TTTS, if left untreated, prior to 24 weeks of gestation, are associated with the loss of one or both twins. In case death of one of the twins occurs, the blood vessel connections in the placenta can place the surviving twin at risk for long-term brain damage. Sonographic criteria for the diagnosis of TTTS as proposed by Harkness and Crombleholme are described in Box $1 .{ }^{22}$

\section{Quintero Stages of TTTS ${ }^{23}$}

\section{Stage I}

A small amount of amniotic fluid (oligohydramnios) is found around the donor twin, and a large amount of amniotic fluid (polyhydramnios) is found around the recipient twin. However, some urine is still visible sonographically within the donor twin's bladder. 

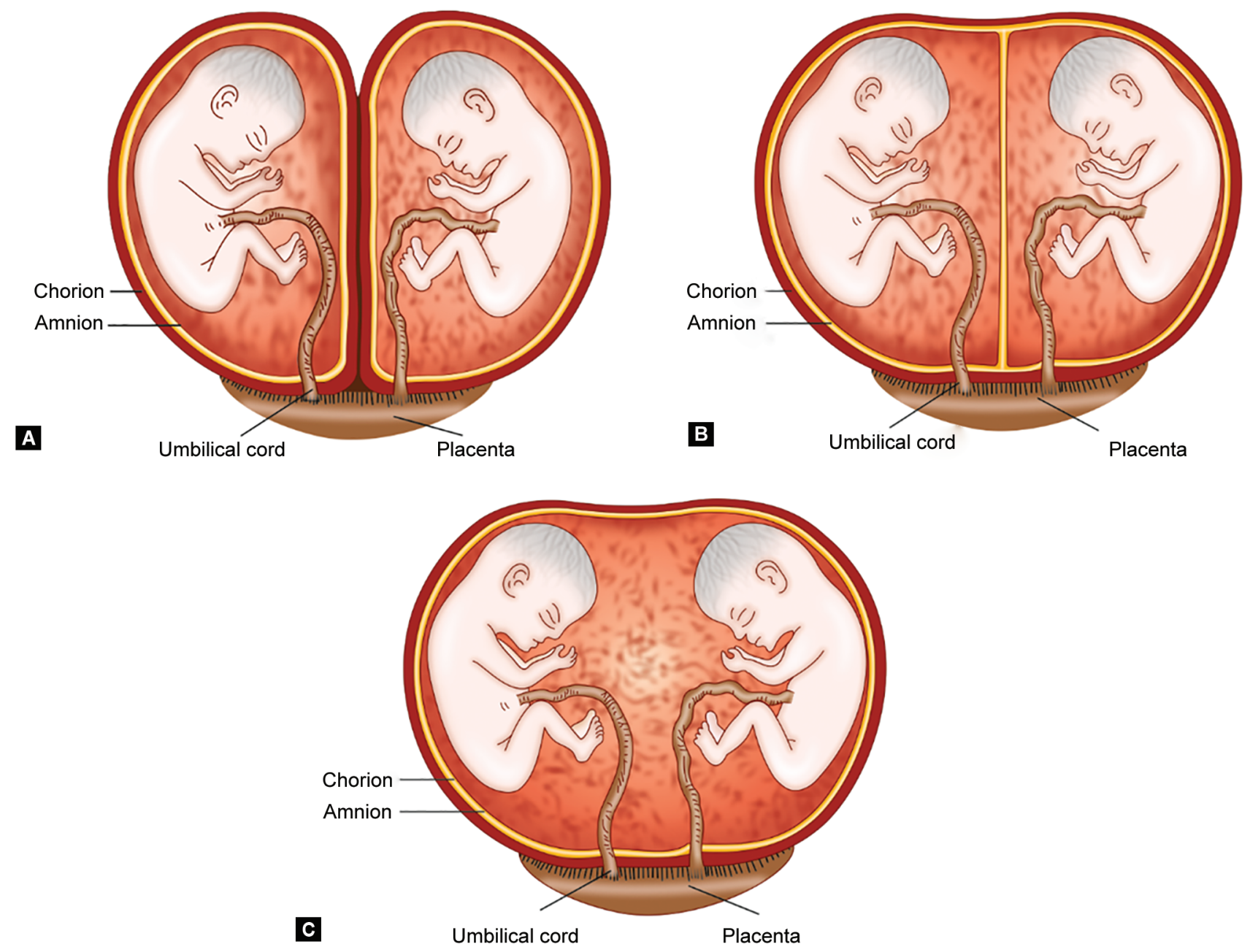

Figs 4A to C: (A) Diamniotic dichorionic monozygotic twin pregnancy; (B) MCDA monozygotic twin pregnancy; (C) Monoamniotic MC monozygotic twin pregnancy
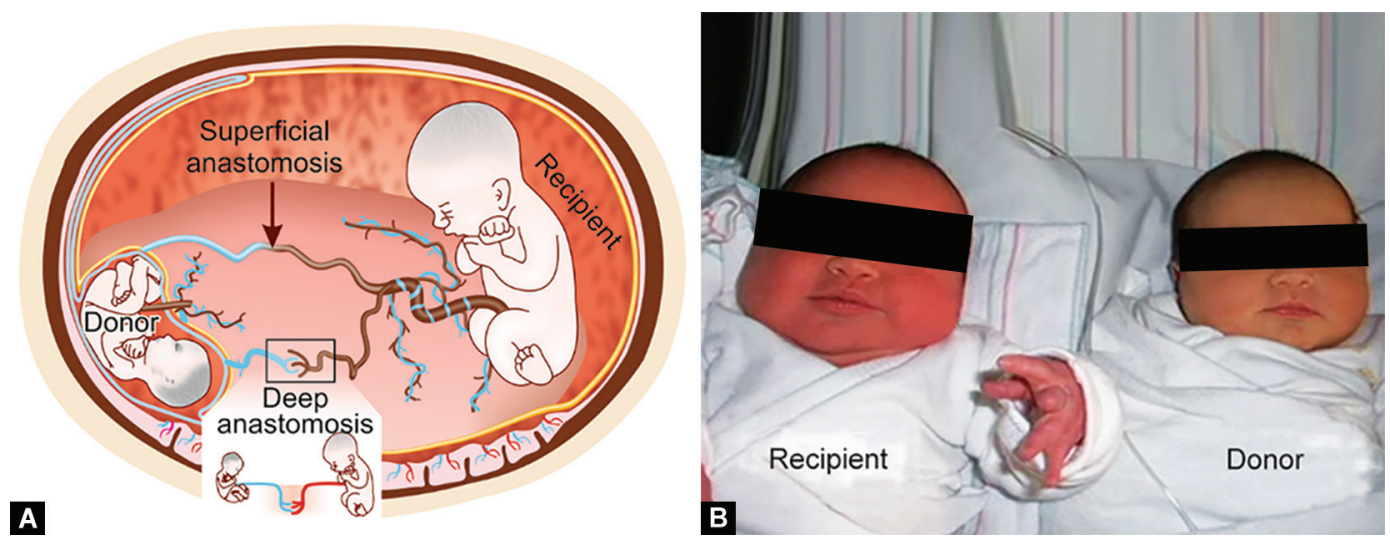

Figs 5A and B:Twin-to-twin transfusion syndrome. (A) Diagrammatic representation; (B) photograph showing the donor and recipient immediately following the delivery

\section{Stage II}

In addition to the presence of above findings, there is absence of urine in the bladder of donor twin on ultrasound examination. In these cases, laser photocoagulation may be helpful.

\section{Stage III}

In addition to the characteristics of stages I and II, Doppler studies are critically abnormal. Critically abnormal Doppler studies are defined as absent/reverse end diastolic velocity in the umbilical 
artery, reverse flow in the ductus venosus, or pulsatile flow in the umbilical vein, ductus venosus, or umbilical artery. Laser photocoagulation is recommended in this situation.

\section{Stage IV}

In addition to all of the above findings, the recipient twin shows evidence of heart failure, ascites or fetal hydrops. Laser photocoagulation may be attempted, but the chance of survival in this stage is much lower.

\section{Stage V}

In addition to all of the above findings, one of the twins has died. Usually the donor twin is the first to die, but death can occur first in either of the twins.

There are a number of limitations of the Quintero staging system; for example, donor twins with a visible bladder might

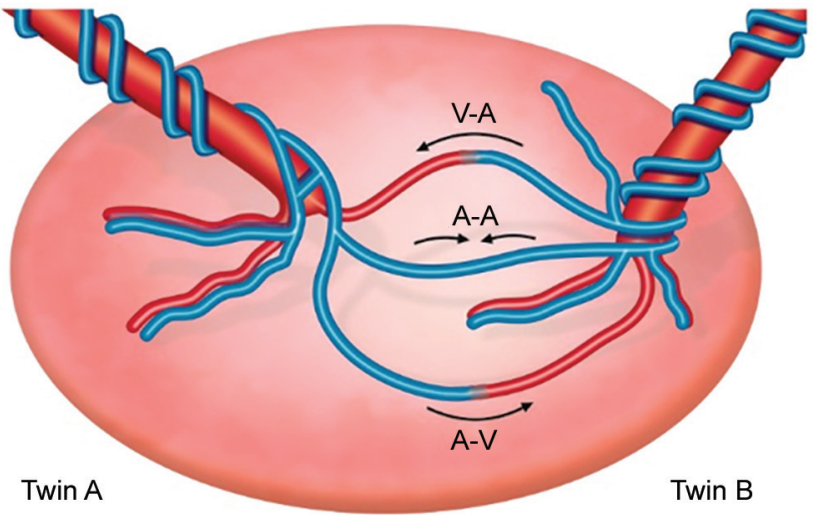

Fig. 6: Diagrammatic representation of placenta showing arteriovenous anastomosis have unusual Doppler findings. Two research groups from the United States, the Children's Hospital of Philadelphia (CHOP score) and the Cincinnati modification of the Quintero system, merged extra cardiovascular parameters for the calculation of neonatal outcome. ${ }^{24,25}$ Their purpose is to build on the conclusion that recipients displayed signs of heart failure even at initial TTTS stages. Wohlmuth et al. evaluated the fetal cardiovascular hemodynamics in TTTS. ${ }^{26,27}$ Up to $70 \%$ of receivers revealed echocardiographic signs of anatomical or functional cardiac compromise. An additional study indicated that cardiac function of the recipient twin was abnormal, even at stage I or II. ${ }^{26}$ In contrast, donor twins normally demonstrate regular cardiac parameters. Though, from the clinical point of view, the Quintero staging system is commonly used even if it does not correspond to a chronological order of deterioration in all cases. Intrauterine fetal death might also take place at stage I without worsening to more advanced stages. To add on, Quintero staging demonstrated a bad estimate of neonatal outcome after laser treatment. Yamamoto et al. completed a longitudinal examination of bladder filling in donors. ${ }^{28}$ They described by definition a visible bladder in stage I but absent voiding dynamics in almost half of the cases, meaning that the difference between stage I and stage II does not reflect the quantity of urine production and in our view does not have any clinical consequence.

\section{Treatment Options}

Since more advanced stages of TTTS have a worse prognosis in comparison with the earlier stages, when severe TTTS occurs at a very early gestational age (prior to 16 weeks), the option of termination of the pregnancy can be considered. The various therapies that are presently available are involving the balancing of the fluid volumes between the two sacs, and interrupting the communication of blood vessels between the twins. The treatment options that are currently available are described below in details. ${ }^{15}$

Flowchart 1: Pathogenesis of TTTS

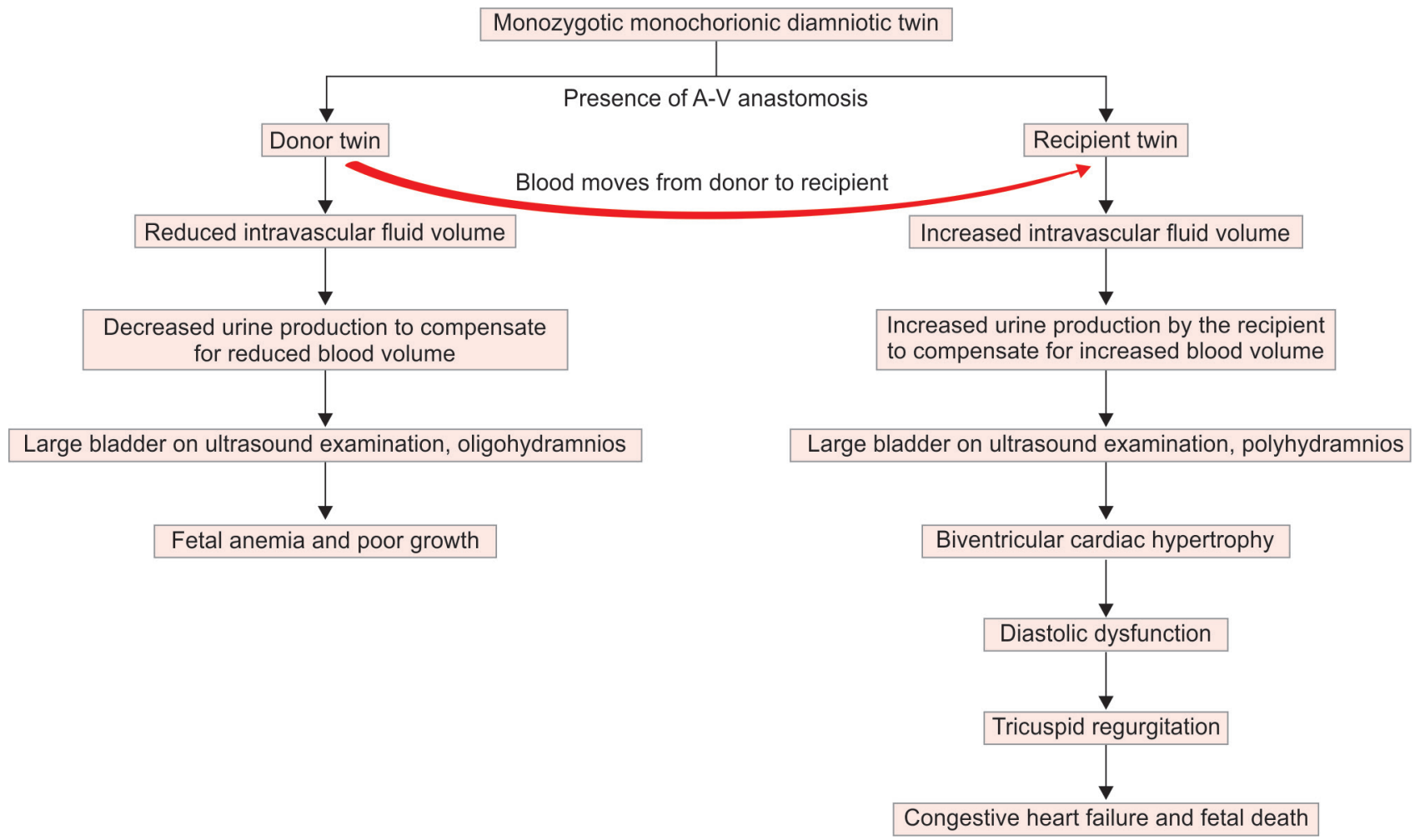


Box 1: Sonographic criteria for the diagnosis of TTTS

- MC twins

- Twins having same gender

- Presence of hydramnios (defined as the largest vertical pocket $>8 \mathrm{~cm}$ ) in one twin and oligohydramnios (defined as the largest vertical pocket is $<2 \mathrm{~cm}$ ) in the other twin

- Discrepancy in the size of umbilical cord between the two twins

- Cardiac dysfunction in the recipient twin along with the presence of hydramnios

- Abnormal findings on the Doppler velocimetry of umbilical vessels or ductus venosus

- Significant discordance of growth among the twins.

\section{Reduction Amniocentesis}

Serial amniocentesis involves the removal of the excessive amount of amniotic fluid from the sac of the recipient twin through the process of amniocentesis. This technique may be useful for milder cases of TTTS that occur later in pregnancy. The procedure is generally not thought to be effective for more advanced stages of TTTS (stages III and IV). As a general rule, no more than $5 \mathrm{~L}$ of amniotic fluid is removed at any one time. The procedure is usually completed within $\mathbf{3 0}$ minutes or less. However, the procedure may only temporarily restore the balance in the amniotic fluid in both twins' sacs as the fluid levels may return within a few days. Thus, the procedure might require to be repeated after every few days. The procedure of repeated amniocenteses for the treatment of TTTS can result in numerous complications such as premature labor, premature rupture of the membranes, and rare infection or abruption. Pregnancies managed with serial reduction amniocentesis on an average deliver by $29-30$ weeks of gestation. ${ }^{6}$

\section{Septostomy (microseptostomy)}

Septostomy involves the creation of a hole in the membrane between the fetal sacs using a needle. This causes the movement of the fluid from the amniotic sac of the recipient into the sac with absent or low fluid (donor's sac). Though the risks for complications like infection, premature labor, and premature rupture of the membranes are rare, septostomy carries the additional potential risk for the hole between the two sacs to become too large. Sometimes, it can cause the entire separating membrane to get disrupted allowing the babies to share the same amniotic space. In the worst case, this could result in entanglement of the umbilical cords of the two twins, resulting in the death of one or both the fetuses. However, the advantage of septostomy over amnioreduction is that the patients undergoing septostomy typically require fewer procedures in comparison with those treated with amnioreduction. ${ }^{19}$

\section{Selective Laser Ablation of the Placental Anastomotic Vessels}

In more advanced stages of TTTS (stage II and higher), ablation of the communicating vessels on the placental surface using laser beams under ultrasound guidance can act as a curative procedure. A fetoscope is introduced in the amniotic cavity after the administration of adequate anesthesia to the patient in order to directly visualize the blood vessels on the surface of the placenta. Vessels that are found to communicate between the twins are then ablated using laser light energy. Being a more invasive procedure in comparison with amnioreduction or septostomy, laser ablation is associated with a higher risk of complications such as premature contractions, premature rupture of the membranes (15-20\% of cases), placental separation (2\%), and infection. In order to prevent these complications, tocolytics to prevent uterine contractions and antibiotics to prevent infection may be given both before and after the procedure. In addition, laser therapy may be associated with unique risks since the laser energy may cause certain areas of the placenta or blood vessels on the surface of the placenta to bleed. Therefore, after laser therapy, close ongoing maternal and fetal surveillance is necessary. ${ }^{9}$

\section{Selective Cord Coagulation}

In this procedure, under ultrasound guidance, one of the twins is purposefully sacrificed in order to save the life of other twin. This procedure is used when laser ablation of the connecting vessels is not possible or if one of the twins is so close to death that laser ablation is unlikely to be successful. By stopping the flow in the cord of the dying twin, the other twin can be protected from the consequences of its sibling's death. In this procedure, the umbilical cord is grasped and electrical current is applied to coagulate the blood vessels in the cord in order to stop the blood flow through them. Complications of this procedure include premature delivery and premature rupture of the membranes. ${ }^{9}$

\section{Selective Fetal Reduction}

This option is considered if severe disturbances in amniotic fluid volume and growth disturbances develop before 20 weeks of gestation. In such cases, due to shared circulation among twins, both fetuses typically will die without any intervention. Various techniques, which may be used for feticide, include injection of an occlusive substance into the selected twin's umbilical vein or radiofrequency ablation, fetoscopic ligation, and laser coagulation of one umbilical cord. Despite these procedures, other fetus remains at appreciable risk. ${ }^{9}$

In 2015, Akkermans et al. ${ }^{29}$ circulated a systematic review comprising 25 years of fetoscopic laser coagulation in TTTS. They briefed the effect of 3,868 women included in 34 studies and stated a large variation between the various fetal medicine centers in terms of case load and outcome. Though, mean survival of both twins and of at least one twin substantially improved from $35 \%$ to $65 \%$ and $70 \%$ to $88 \%$, respectively. The mean gestational age at birth of all series was $32.4 \pm 1.3$ weeks.

Another essential feature is neurodevelopmental follow-up studies in survivors. Fetal brain lesions following laser surgery may be portrayed by prenatal ultrasound or MRI. The lesions may be ischemic or hemorrhagic, and the prevalence is roughly $2 \%$ (equally allocated in donors and recipients). Substantial risk factors are recurrent TTTS and postlaser TAPS following incomplete laser surgery. ${ }^{30}$ van Klink et al. showed that severe cerebral injury at birth was independently associated with neurodevelopment impairment at 2 years of age. ${ }^{31}$ Schou et al. investigated the prevalence of severe neurodevelopment impairment (cerebral palsy, bilateral blindness and/or deafness, and severe cognitive and/or motor delay) in children at the age of 2 years after fetoscopic laser surgery for TTTS. ${ }^{32}$ Nine out of 86 children (10.5\%) were affected. It is important to know that follow-up studies reported varying rates of cerebral palsy and neurodevelopment impairment in TTTS treated cases with laser surgery. This may be due to different methodology, heterogeneity within small case series, and lack of uniform outcome criteria. 
Van Klink summarized 13 studies and found a prevalence of $6.1 \%$ for cerebral palsy and $9.8 \%$ neurodevelopmental impairment. ${ }^{33}$ Preterm delivery was an independent risk factor for neurodevelopmental impairment after laser treatment. ${ }^{34}$ Other important risk factors were increased gestational age at intervention, higher Quintero stage, perinatal severe cerebral injury, and low birthweight. ${ }^{33,35}$ Twins with TTTS have the highest risk for congenital heart defects in comparison with uncomplicated MC twins and singletons. The prevalence of heart disease in children after laser therapy was investigated in cohort studies. Herberg et al. found a structural heart defect in $6(9.7 \%)$ out of 62 survivors at the age of 10 years. ${ }^{36}$ Pulmonary stenosis was the main finding and detected in five cases, both in former recipient and donor twins. ${ }^{37-39}$

Unfortunately, many cases of TTTS worldwide are still left untreated. A global survey of 64 centers of fetal therapy units offering laser treatment for TTTS identified 33 high-volume ( $>20$ procedures annually) and 31 low-volume ( $<20$ procedures annually) units, respectively. The investigators found a striking difference between the two groups in terms of the geographic location. Lowvolume centers were more frequently located in South America, Australia, and the Middle East $(p<0.01)$. In contrast, $79 \%$ of the 19 European fetoscopic centers were high volume units. Therefore, some regions may have difficulties to establish and run high volume centers offering laser treatment in TTTS. Meanwhile, international collaborations with the goal to provide timely access to treatment is a main challenge. ${ }^{40-42}$

\section{ConcLusion}

In conclusion, fetoscopic laser coagulation is the gold standard for treatment of severe TTTS at mid-gestation (16-26 weeks). There is some indication that early and late laser interventions are achievable and might enhance the outcome. Some fetal medicine centers are able to provide the conservative treatment with close supervision to the stage ITTTS. However, shortening of the cervix, maternal discomfort, and increasing polyhydramnios are the criteria in order to perform laser treatment. Following the introduction of fetoscopic laser surgery for TTTS 25 years ago, perinatal mortality was significantly reduced. High-volume centers are able to achieve $70 \%$ double twin survival and survival of at least one twin in $>90 \%$ of cases after fetoscopic laser treatment. In order to achieve that, laser therapy should be centralized in specialized centers performing at least 20 procedures per surgeon annually. Prospective registration and standardized long-term outcome studies are very important. ${ }^{43,44}$ It will be exciting if noninvasive treatment for TTTS will be viable in the future. Meanwhile technical advances in terms of flexible scopes can enhance the visualization and coagulation of all anastomoses.

\section{References}

1. Armson BA, O'Connell C, Persad V, et al. Determinants of perinatal mortality and serious neonatal morbidity in the second twin. Obstet Gynecol 2006;108(3 Pt 1):556-564. DOI: 10.1097/01. AOG.0000227747.37184.0a.

2. Bdolah Y, Lam C, Rajkumar A, et al. Twin pregnancy and the risk of preeclampsia: bigger placenta or relative ischemia? Am J Obstet Gynecol 2008;198(4):428.e1-428.e6. DOI: 10.1016/j.ajog.2007. 10.783.

3. Bhide A, Thilaganathan B. What prenatal diagnosis should be offered in multiple pregnancy? Best Pract Res Clin Obstet Gynaecol 2004;18(4):531-542. DOI: 10.1016/j.bpobgyn.2004.04.012.
4. Young $B C$, Wylie BJ. Effects of twin gestation on maternal morbidity. Semin Perinatol 2012;36(3):162-168. DOI: 10.1053/ j.semperi.2012.02.007.

5. Walker MC, Murphy KE, Pan S, et al. Adverse maternal outcomes in multifetal pregnancies. BJOG 2004;111(11):1294-1296. DOI: 10.1111/j.1471-0528.2004.00345.x.

6. National Institute for Health and Clinical Excellence. (2011). Multiple Pregnancy: The Management of Twin and Triplet Pregnancies in the Antenatal Period. [online] Available from https://www.nice.org.uk/ guidance/cg129, Last Accessed November, 2019.

7. Buhling KJ, Henrich W, Starr E, et al. Risk for gestational diabetes and hypertension for women with twin pregnancy compared to singleton pregnancy. Arch Gynecol Obstet 2003;269(1):33-36. DOI: 10.1007/ s00404-003-0483-z.

8. Obiechina NJ, Okolie V, Eleje G, et al. Twin versus singleton pregnancies: the incidence, pregnancy complications, and obstetric outcomes in a Nigerian tertiary hospital. Int J Women's Health 2011;3:227-230. DOI: 10.2147/IJWH.S22059.

9. Campbell DM. Multiple pregnancy. Baillieres Clin Obstet Gynaecol 1990;4(1):109-127. DOI: 10.1016/S0950-3552(05)80215-9.

10. Sperling L. Detection of chromosomal abnormalities, congenital abnormalities and transfusion syndrome in twins. Ultrasound Obstet Gynecol 2007;29(5):517-526. DOI: 10.1002/uog.3918.

11. Dodd JM, Crowther CA. Reduction of the number of fetuses for women with a multiple pregnancy. Cochrane Database Syst Rev 2012;10:CD003932.

12. Schmitz T, Carnavalet Cde C, Azria E, et al. Neonatal outcomes of twin pregnancy according to the planned mode of delivery. Obstet Gynecol 2008;111(3):695-703. DOI: 10.1097/AOG.0b013e318163c435.

13. Wimalasundera RC, Trew G, Fisk NM. Reducing the incidence of twins and triplets. Best Pract Res Clin Obstet Gynaecol 2003;17(2):309-329. DOI: 10.1016/S1521-6934(02)00135-9.

14. Hack KE, Derks JB, Elias SG, et al. Increased perinatal mortality and morbidity in monochorionic versus dichorionic twin pregnancies: clinical implications of a large Dutch cohort study. BJOG 2008;115(1):58-67. DOI: 10.1111/j.1471-0528.2007.01556.x.

15. Consensus views arising from the 50th study group: multiple pregnancy. In: Kilby M, Baker P, Critchley H, et al. Multiple Pregnancy. London: RCOG Press; 2006. pp. 283-286.

16. De Paepe ME, Luks FI. What-and why-the pathologist should know about twin-to-twin transfusion syndrome. Pediatr Dev Pathol 2013;16:237-251. DOI: 10.2350/13-03-1315-MISC.1.

17. De Lia JE, Kuhlmann RS. Twin-to-twin transfusion syndrome-30 years at the front. Am J Perinatol 2014;31(Suppl 1):S7-S12. DOI: 10.1055/s-0034-1376184.

18. Baschat A, Chmait RH, Deprest J, et al. Twin-to-twin transfusion syndrome (TTTS). J Perinat Med 2011;39:107-112.

19. Simpson LL. Society for maternal-fetal medicine (SMFM). Twin-twin transfusion syndrome. Am J Obstet Gynecol 2013;208:3-18. DOI: 10.1016/j.ajog.2012.10.880.

20. Diehl W, Diemert A, Glosemeyer P, et al. OP06. 02: development of survival rates after intrauterine laser therapy for severe mid-trimester twin-twin transfusion syndrome: experience with 600 cases. Ultrasound Obst Gyn 2010;36:67. DOI: 10.1002/uog.7974.

21. Zhao DP, de Villiers SF, Slaghekke F, et al. Prevalence, size, number and localization of vascular anastomoses in monochorionic placentas. Placenta 2013;34(7):589-593. DOI: 10.1016/j.placenta.2013.04.005.

22. Harkness UF, Crombleholme TM. Twin-twin transfusion syndrome: Where do we go from here? Semin Perinatol 2005;29(5):296-304. DOI: 10.1053/j.semperi.2005.10.001.

23. Quintero RA, Morales WJ, Allen $\mathrm{MH}$, et al. Staging of twin-twin transfusion syndrome. J Perinatol 1999;19(8 Pt 1):550-555. DOI: 10.1038/sj.jp.7200292.

24. Michelfelder E, Gottliebson W, Border W, et al. Early manifestations and spectrum of recipient twin cardiomyopathy in twin-twin transfusion syndrome: relation to quintero stage. Ultrasound Obstet Gynecol 2007;30(7):965-971. DOI: 10.1002/uog.5211. 
25. Rychik J, Tian Z, Bebbington $M$, et al. The twin-twin transfusion syndrome: spectrum of cardiovascular abnormality and development of a cardiovascular score to assess severity of disease. Am J Obstet Gynecol 2007;197(4):392.e1-408.e1. DOI: 10.1016/j.ajog.2007.06.055.

26. Wohlmuth C, Gardiner HM, Diehl W, et al. Fetal cardiovascular hemodynamics in twin-twin transfusion syndrome. Acta Obstet Gynecol Scand 2016;95(6):664-671. DOI: 10.1111/aogs.12871.

27. Wohlmuth C, Boudreaux D, Moise JrKJ, et al. Cardiac pathophysiology in twin-twin transfusion syndrome: new insights into its evolution. Ultrasound Obstet Gynecol 2018;51(3):341-348. DOI: 10.1002/ uog. 17480

28. Yamamoto M, Essaoui M, Nasr B, et al. Three-dimensional sonographic assessment of fetal urine production before and after laser surgery in twin-to-twin transfusion syndrome. Ultrasound Obstet Gynecol 2007;30(7):972-976. DOI: 10.1002/uog.5218.

29. Akkermans J, Peeters SH, Klumper FJ, et al. Twenty-five years of fetoscopic laser coagulation in twin-twin transfusion syndrome: a systematic review. Fetal Diagn Ther 2015;38:241-253. DOI: 10.1159/ 000437053.

30. Stirnemann J, Chalouhi G, Essaoui M, etal. Fetal brain imaging following laser surgery in twin-to-twin surgery. BJOG 2016;125(9):1186-1191. DOI: 10.1111/1471-0528.14162.

31. van Klink JM, Koopman HM, van Zwet EW, et al. Improvement in neurodevelopmental outcome in survivors of twin-twin transfusion syndrome treated with laser surgery. Am J Obstet Gynecol 2014;210(6):e541-e547. DOI: 10.1016/j.ajog.2014.01.002.

32. Schou KV, Lando AV, Ekelund CK, etal. Long-term neurodevelopmental outcome of monochorionic twins after laser therapy or umbilical cord occlusion for twin-twin transfusion syndrome. Fetal Diagn Ther 2019;46(1):20-27. DOI: 10.1159/000491787.

33. van Klink JM, Koopman HM, Rijken M, et al. Long-term neurodevelopmental outcome in survivors of twin-to-twin transfusion syndrome. Twin Res Hum Genet 2016;19(3):255-261. DOI: 10.1017/thg.2016.26.

34. Lenclen R, Paupe A, Ciarlo G, et al. Neonatal outcome in preterm monochorionic twins with twin-to-twin transfusion syndrome after intrauterine treatment with amnioreduction or fetoscopic laser surgery: comparison with dichorionic twins. Am J Obstet Gynecol 2007;196(5):e451-e457. DOI: 10.1016/j.ajog.2007.01.036.
35. Lopriore E, Ortibus E, Acosta-Rojas R, et al. Risk factors for neurodevelopment impairment in twin-twin transfusion syndrome treated with fetoscopic laser surgery. Obstet Gynecol 2009;113(2 Pt 1): 361-366. DOI: 10.1097/AOG.0b013e318195873e.

36. Herberg U, Bolay J, Graeve P, et al. Intertwin cardiac status at 10 -year follow-up after intrauterine laser coagulation therapy of severe twin-twin transfusion syndrome: comparison of donor, recipient and normal values. Arch Dis Child Fetal Neonatal Ed 2014;99(5): F380-F385. DOI: 10.1136/archdischild-2013-305034.

37. Bebbington M. Twin-to-twin transfusion syndrome: current understanding of pathophysiology, in-utero therapy and impact for future development. Semin Fetal Neonatal Med 2010;15(1):15-20. DOI: $10.1016 / j . \operatorname{siny} .2009 .05 .001$

38. Zikulnig L, Hecher K, Bregenzer T, et al. Prognostic factors in severe twin-twin transfusion syndrome treated by endoscopic laser surgery. Ultrasound Obstet Gynecol 1999;14(6):380-387. DOI: 10.1046/j.14690705.1999.14060380.x.

39. Gratacós E, Van SchoubroeckD, Carreras E. Impact of laser coagulation in severe twin-twin transfusion syndrome on fetal doppler indices and venous blood flow volume. Ultrasound Obstet Gynecol 2002;20(2):125-130. DOI: 10.1046/j.1469-0705.2002.00749.x.

40. Mackie FL, Hall MJ, Morris RK, et al. Early prognostic factors of outcomes in monochorionic twin pregnancy: systematic review and meta-analysis. Am J Obstet Gynecol 2018;219(5):436-446. DOI: 10.1016/j.ajog.2018.05.008.

41. Stagnati V, Zanardini C, Fichera A, et al. Early prediction of twin-totwin transfusion syndrome: systematic review and meta-analysis. Ultrasound Obstet Gynecol 2017;49(5):573-582. DOI: 10.1002/ uog. 15989

42. Akkermans J, Peeters SH, Middeldorp JM, et al. A worldwide survey of laser surgery for twin-twin transfusion syndrome. Ultrasound Obstet Gynecol 2015;45(2):168-174. DOI: 10.1002/uog.14670.

43. Taylor MJ. The management of multiple pregnancy. Early Hum Dev 2006;82(6):365-370. DOI: 10.1016/j.earlhumdev.2006.03.008.

44. Perry H, Duffy JMN, Umadia O, et al. Outcome reporting across randomized trials and observational studies evaluating treatments for twin-twin transfusion syndrome: systematic review. Ultrasound Obstet Gynecol 2018;52(5):577-585. DOI: 10.1002/uog. 19068. 